\title{
Reducing Hospital ICU Noise: A Behavior-Based Approach
}

\author{
Avinash Konkani, BE, MS ${ }^{1,2 *}$; Barbara Oakley, PhD, PE, FAIMBE ${ }^{1}$; and \\ Barbara Penprase; PhD, RN, $\mathrm{CNE}^{3}$ \\ ${ }^{I}$ Department of Industrial and Systems Engineering, Oakland University, \\ Rochester, MI, USA \\ ${ }^{2}$ Department of Clinical Engineering, University of Virginia Health System, \\ Charlottesville, VA, USA \\ ${ }^{3}$ School of Nursing, Oakland University, Rochester, MI, USA
}

Submitted August 2013. Accepted for publication February 2014.

\begin{abstract}
Noise in Intensive Care Units (ICUs) is gaining increasing attention as a significant source of stress and fatigue for nursing staff. Extensive research indicates that hospital noise also has negative impact on patients. The objective of this study was to analyze noise variations as experienced by both nursing staff and patients, to gain a better understanding of noise levels and frequencies observed in ICU settings over extended (week-long) durations, and to implement a low cost behavior modification program to reduce noise. The results of our study indicate that behavioral modification alone is not adequate to control excessive noise. There is a need for further research involving the supportive involvement by clinicians, ICU staff, along with effective medical device alarm management, and continuous process improvement methods.
\end{abstract}

Keywords: hospital noise, noise pollution, occupational noise, patient safety, performance obstacle, occupational stress

\section{INTRODUCTION}

An Intensive Care Unit (ICU) is a special area designed to treat hospital patients who are at substantial risk for death. A typical ICU consists of individual patient rooms containing equipment such as ventilators, patient monitors, infusion pumps, syringe pumps, humidifiers, nebulizers, suction and dialysis machines-all supported with a complex arrangement of cables, wires, and tubes that are in turn located on carts, wall racks, and trays. Such a layout creates an obstacle course for nurses as they perform their multi-patient duties in different rooms within the ICU. From a researcher's perspective, an ICU shares ergonomic considerations with an airplane pilot's cockpit. There are times when every motion counts-intelligent layout as well as timely and accurate processing of the information is vital for high quality patient care and safety.

\footnotetext{
* Corresponding author: Avinash Konkani, Oakland University, Department of Industrial and Systems Engineering, 2200 North Squirrel Road, Rochester, MI 48309. Phone: (248) 370-2989. Fax: (248) 3702699. E-mail: akonkani@oakland.edu

Other authors: Oakley@oakland.edu; penprase@oakland.edu
} 
A particularly important consideration is the auditory environment of the ICU. A typical ICU is bombarded with an array of buzzers, pagers, telephones, alarms, and beeps. The air is filled also with the conversation of medical professionals, patients and family. Together, this creates a cacophony that can create a highly unpleasant and unhealthy work environment for doctors and nurses, not to mention the patients they are caring for. One study involving 272 nurses from 17 ICUs at seven hospitals found that $46 \%$ (nearly 125) of nurses agreed that a noisy work environment is one of the top performance obstacles for ICU nurses [1]. In a major review study done in 2010, Choiniere found multiple studies indicating that noise has physiological and psychological effects on the body, and increasing noise level has the potential to increase complications in patients [2]. A recent 2012 clinical review study on noise pollution in hospitals highlighted a number of potentially negative effects of hospital noise on staff, concluding that "The need for more research in this area is acute, particularly given that many of the results that do exist raise serious concerns" [3]. Padmakumar et al. concluded that higher noise levels affect the recovery and sleep of the patients, and also have a negative effect on communication, speech intelligibility and stress levels of the ICU staff [4].

\subsection{Sources of Noise}

Research literature suggests that staff conversations and medical equipment alarms appear to be the most disturbing noise sources in the ICU [5-8]. Noise also arises from building ventilation systems; closing and opening of doors and drawers; telephones; mobile phones; pagers; overhead speakers; televisions; closing of metallic dust bins; squeaking wheels of patient beds or wheel chairs; vacuum cleaners; and the pneumatic tube systems used for delivery of drugs, documents, and specimens between the laboratories and ICU [5, 7, 9-21].

Most previous studies related to noise in hospitals have focused on analyzing general noise (sound) pressure levels rather than on understanding how those sound pressure levels vary with respect to their frequency components [4, 5, 7, 10, 12, 19-24], despite the fact that different frequencies have differing effects on people, and a variety of methods must be used to mitigate the effect of sounds at different frequencies.

Relevant to all this is that the human ear is more sensitive to high- than to lowfrequency sounds. As people age, their sensitivity to higher frequencies decreases [25]. However, low frequency noise can also have negative health effects [26]. It is important to note that although our audible frequency range is 20 to $20,000 \mathrm{~Hz}$, human ears are more sensitive to sounds in the range of 1000 to $4000 \mathrm{~Hz}$ [27]. It therefore is particularly important to reduce noise in this frequency range so as to improve speech intelligibility (a measure of how easily people can have effective verbal communication). In a 2013 article on hospital noise and hearing, Pope and her colleagues stated that the impact of increased hospital noise on patient's "ability to hear, understand and recall" information conveyed by the clinicians to the patients has not been adequately researched [28]. Their study results supported the fact that decreasing the noise levels will increase the speech intelligibility [28]. These findings were echoed by Ryherd et al. (2013), who concluded that none of the five hospital's twenty units 
showed a good average speech intelligibility rating. Nursing stations in particular recorded poor speech intelligibility ratings [29]. These studies clearly indicate the negative effect of hospital noise on effective communication and its impact on patient care and safety.

\subsection{Physiological Effects of Noise}

Noise has adverse cardiovascular and other physiological effects, and psychological effects such as headaches, anxiety, emotional stress, and burnout [2-4, 16, 30-33]. In her review study, Choiniere mentioned that nurses spend far more time in ICU's than patients, meaning the nursing staff experiences more exposure to excessive noise levels than patients - yet the long term effect of noise on nursing staff is not well known [2]. Another study by Ryherd et al. (2012) also supported the fact that the hospital noise has adverse effects on the employee's stress, satisfaction, psychological environment, job performance and health [3]. Excessive noise affects not only the work performance of clinicians and reduces patient safety, but also affects patient's healing processes and disturbs the patient's sleep. Morrison et al. (2003) observed that noise is an important contributor for increased heart rates, tachycardia, stress and annoyance in nursing staff [6]. A critical review published supports the fact that ICU's have become noisy and states that behavior modification programs with educational sessions are the most widely practiced and inexpensive interventions for reducing noise levels in the hospitals [34]. These findings were also supported by Padmakumar and his colleagues completed at two large teaching hospitals in U.K. [4].

The issue of increased hospital noise and its adverse effects on the patient and staff has not only been highlighted in scientific journals, but also in the national media. For example, in the years 2011-2013, The Boston Globe, The Wall Street Journal, The Washington Post, Fox News, and ABC News have published articles or featured news stories on hospital noise [35-40]. It is clear that the general public is also aware of this problem.

\subsection{Methods of Noise Control}

There are three standard methods for controlling noise: 1) at the source, which is generally considered the best method, 2) along the path between the source and the receiver, and 3) at the receiver [41, 42]. Since people and equipment are the major source of noise in the ICU, we applied the low cost behavioral modification method as an ergonomic intervention to reduce noise at the source.

It is a difficult and costly affair to apply structural changes in the existing ICU's, as suggested with the second method of noise control [42]. For example, in our study, the Pediatric Intensive Care Unit (PICU) nursing station's roof has the shape of an arc, which generates echoes. Unfortunately, the estimated cost to replace the arc with a flat roof was $\$ 20,000$ (US) — out of range for this project's budget.

As far as the receivers go, two studies used the earplugs/earmuffs for patients and found a $39.0 \%$ and $33.7 \%$ improvement in the patient's sleep [43, 44]. Earplugs/earmuffs may be good for patients for short periods, but they are not good for long term usage. Earplugs/earmuffs may introduce infection control concerns. 
Unfortunately, healthcare providers themselves (e.g., nurses and other staff), cannot use ear plugs as a method to control the noise at the receiver in hospital ICU settings. Ultimately, in consideration of all these factors, it is important to control the noise levels at the source rather than in the path or at the receiver.

\subsection{Study Objectives}

With this background in mind, we designed a study with the following objectives:

- To quantify noise levels and their variability within a large hospital's PICU so as to better understand the noise levels experienced by the patients as well as the nursing staff.

- To carry out an amplitude and frequency analysis of the noise, and to determine optimal methods to reduce noise corresponding to the frequencies with highest sound pressure levels.

- To implement appropriate low- or no-cost sound reduction measures, including behavioral modification program, to reduce the noise.

- To quantify the change in noise levels within the ICU after implementing sound reduction measures, thus obtaining a before and after set of measures of the effectiveness of the behavior modification program.

\section{METHODS}

\subsection{Experimental Design and Study Approval}

The study was approved by the Human Investigation Committee of the hospital (HIC\#2011-131) and the Institutional Review Board of the Oakland University (IRB application \# 4764). A detailed information sheet was circulated to all the nursing staff and a copy was placed on the notice board of the PICU.

The study was conducted in a large teaching hospital in southeast Michigan, which has an eight-bed PICU with private rooms for each patient. The private room design of an ICU provides for better noise control as compared to multi-bed rooms (shared rooms) ICUs [45-47].

The PICU is structured in the shape of the letter "H." The nursing station is located centrally between the two parallel walkways. The floor of the walkways and the nursing station is covered with carpet, which is good for sound absorption, but keeping the carpets clean requires frequent use of a noisy vacuum cleaner. The patient rooms, on the other hand, have tiled floors, that are not good for sound absorption, but allow for keeping the floor clean and infection free.

The PICU has two shifts per day with twelve hours per shift: a day shift (7:00 AM to 7:00 PM) and a night shift (7:00 PM to 7:00 AM). Noise levels in three stationary and two mobile locations within the PICU were assessed by noise level meters: (a) two patient rooms (stationary); (b) the nursing station (stationary); and (c) throughout the PICU as experienced by two Registered Nurses (RNs). Due to space constraints, the noise level meter at the nursing station was kept on a tripod below the nursing desk, about 2.5 feet above the floor. The two patient rooms were selected by the assistant nurse manager depending on the patient's condition (e.g., highly critical patient rooms were not selected) and the family members' permission to 
place the sound level meters. The same rooms were used for the entire week of data collection, unless the patient in the room was discharged from the PICU and no subsequent patient was immediately placed in that room. Therefore, the sound level meters were never left for recording in a no-patient room. The noise meters were placed on tripod and were close to the patient's head level. The noise meters were moved between the patient rooms in consultation with the nursing staff.

The data from these five locations/personnel were gathered to understand the variation in the noise characteristics and to determine whether observed noise levels would exceed World Health Organization (WHO) and the United States Environmental Protection Agency (EPA) recommended limits for hospitals. We simultaneously conducted a frequency analysis of the noise in the PICU to determine which frequencies were associated with higher sound pressure levels, measured in decibels.

In our study, we followed the classification of frequencies as stated by Berglund et al. (1996), and interpreted low frequencies as ranging from 20 to $250 \mathrm{~Hz}$, while high frequencies ranging from 251 to $20,000 \mathrm{~Hz}$.

\subsection{Data Collection Process}

Data were collected in three separate one-week time frames from August, 2011 to February 2012. During each time frame, data were collected for seven consecutive days per week for 3 separate weeks, with a total of 504 hours $(24 \mathrm{hrs} /$ day $\times 7$ days $/ \mathrm{wk} \times 3 \mathrm{wk}=504$ hours).

1) Baseline data (first set of data): The first set of data was collected in the last week of August, 2011, to estimate the noise levels in the PICU before intervention.

2) Second set of data: The second set of data was collected seven weeks after noise reduction techniques (i.e., behavior modification) had been implemented so as to estimate effect of those techniques.

3) Third set of data: Fifteen weeks after noise reduction techniques were implemented, a third set of data was collected to estimate the longer term effect of the noise reduction techniques.

\subsection{Instruments and Measurements}

Our objective was to estimate the noise levels as experienced by the nursing staff as well as patients, and the variation of noise levels during the 12 hours day/night shifts, in order to compare the variation of noise levels in these shifts and throughout the week. Data collection from the stationary locations in the PICU was accomplished using the Optimus Red Class-2 Integrating Sound Level Meters (ISLM's) (CR:162C) with data logging and octave-band filters from Cirrus Research plc (United Kingdom). These devices are classified as Type 2 under IEC61672-1:2002 standard. These class- 2 sound level meters have an accuracy of $\pm 2 \mathrm{dBA}$. The sound level meters were heavy and needed a continuous power supply; hence we placed them on a tripod at the height of patient's head, approximately one meter above the ground. DoseBadge Noise Dosimeters (CR:110A, Cirrus Research plc) were used to collect the noise levels experienced by the two voluntary Registered Nurses (RNs) on duty in each shift. Each $\mathrm{RN}$ wore the dose badge on a shoulder and near an ear. 
The software package "noisetools" (version 1.4.3.1629) was used for data analysis from the sound level meters, while the "dBlink" package (version 3.3) was used for data analysis from the doseBadge noise dosimeters. Before every measurement, both the sound level meters and dosimeters were calibrated using the calibrators provided by Cirrus Research plc.

The equivalent continuous noise level $\mathrm{L}_{\mathrm{eq}}$ was measured during the data collection period. This is the average exposure level over the run time. The $\mathrm{L}_{\mathrm{eq}}$ measured in $\mathrm{dBA}$ is denoted as $\mathrm{L}_{\mathrm{Aeq}}$. If it is measured over a period of ' $\mathrm{T}$ ' hours, it is denoted as $\mathrm{L}_{\mathrm{Aeq}, \mathrm{T}}$. In this study, we measured the $\mathrm{L}_{\text {Aeq }}$ over 12 hour periods, annotated as $\mathrm{L}_{\mathrm{Aeq}, 12 \mathrm{~h}}$. The peak sound levels were also measured and are denoted in our study as $\mathrm{L}_{\text {CPeak }}$. When sound is measured with an A-weighting filter, it is denoted as dBA, whereas if it is measured with $\mathrm{C}$-weighting filters, it is denoted as $\mathrm{dBC}$. The WHO and the EPA have established noise level guidelines for the hospital environment in dimensional units of $\mathrm{L}_{\text {Aeq,T; }}$; therefore it is important to measure the noise levels in $\mathrm{L}_{\text {Aeq,T }}[30,48,49]$.

\subsection{Behavioral Modification Program and Noise Reduction Methods}

In the behavioral modification program, we used a noise warning device, the "SoundEar," that measures the noise in the area and gives a visual signal when the noise exceeds a set limit. Using this device, the nurses and other staff were trained to try to reduce controllable noise levels whenever they saw a high noise signal on the noise warning sign. Three SoundEar devices were used. The SoundEar operates as follows: Yellow indicators light up once the noise level reaches $45 \mathrm{dBA}$, while red indicators light at $50 \mathrm{dBA}$. These warning signs remain "ON" unless and until the noise level falls below $45 \mathrm{dBA}$. One SoundEar was placed on the wall at the nursing station, while the other two were placed on the walls of the walkways on either side of the nursing station. This ensured that everyone in the H-shaped PICU could easily see these devices at all times.

The behavior modification intervention included increasing staff awareness about the potentially negative impact of noise on patients and staff. Nursing staff were educated directly with a Power Point presentation, a poster that summarized the main ideas of the Power Point Presentation, and/or an email to nursing staff with the Power Point presentation attached, which covered the off-shift staff and varyingschedules ICU nurses. In these training outreach efforts, suggestions were made to reduce noise levels using techniques such as reducing the volume level of telephone ringers and televisions; keeping the mobile phones and pagers in vibrating mode; trying to minimize conversation near bed sides and the nursing station; implementing quiet periods during each shift; and holding clinical discussions and shift reporting in the conference room which is located at a distance from the patient rooms and the nursing station.

The poster was kept in the conference room. The thirty-minute presentation was given to a committee of six nursing staff, including the nurse manager and associate nurse manager of PICU. There was a brief discussion after the presentation. These interactions ensured that the nursing staff was involved in the design and implementation of the study. 


\section{RESULTS}

\subsection{Amplitude Analysis of Noise}

To better understand noise level variation within the PICU, we compared noise levels from the nursing station (NS), the two patient rooms (PR $1 \&$ PR 2) and as experienced by two Registered Nurse (RN1 \& RN2) staff.

From Tables 1, 2 and 3, it is clear that the nursing staff experiences excessive noise $\left(\mathrm{L}_{\text {Aeq,12h }}\right)$. The overall variation of the noise levels $\left(\mathrm{L}_{\text {Aeq }}\right)$ was in the range of 47 dBA (Night-Minimum in PR 1) to 77 dBA (Day-Maximum for RN 1) during the

Table 1. Equivalent continuous noise $L_{A e q, 12 h}$ measured for 7 days at baseline (All data in dBA)

\begin{tabular}{lccccc}
\hline Baseline & & Day-Min & Day-Max & Night-Min & Night-Max \\
\hline Location & RN 1 & 63 & 77 & 58 & 70 \\
& RN 2 & 60 & 72 & 61 & 70 \\
& PR 1 & 60 & 69 & 47 & 62 \\
& PR 2 & 52 & 60 & 48 & 57 \\
& NS & 56 & 59 & 52 & 55 \\
\hline
\end{tabular}

(RN - Registered Nurse, PR- Patient Room, NS - Nurse Station, Day-Min - the minimum value of $\mathrm{L}_{\mathrm{Aeq}, 12 \mathrm{~h}}$ in the day shift. Day-Max - the maximum value of $\mathrm{L}_{\mathrm{Aeq}, 12 \mathrm{~h}}$ in the day shift, Night-Min - the minimum value of $\mathrm{L}_{\text {Aeq, } 12 \mathrm{~h}}$ in the night shift, Night-Max - the maximum value of $\mathrm{L}_{\text {Aeq, 12h }}$ in the night shift.)

Table 2. Equivalent continuous noise $\mathrm{L}_{\mathrm{Aeq}, 12 \mathrm{~h}}$ measured for 7 days, 7 weeks after the beginning of intervention (All data in $\mathrm{dBA}$ )

\begin{tabular}{lccccc}
\hline After 7 weeks & & Day-Min & Day-Max & Night-Min & Night-Max \\
\hline Location & RN 1 & 68 & 81 & 67 & 73 \\
& RN 2 & 70 & 77 & 67 & 74 \\
& PR 1 & 54 & 58 & 52 & 54 \\
& PR 2 & 51 & 58 & 49 & 57 \\
NS & 54 & 58 & 52 & 55 \\
\hline
\end{tabular}

(RN - Registered Nurse, PR- Patient Room, NS- Nurse Station)

Table 3. Equivalent continuous noise $L_{A e q, 12 h}$ measured for 7 days, 15 weeks after the beginning of the intervention (All data in $\mathrm{dBA}$ )

\begin{tabular}{lccccc}
\hline After-15 weeks-3rd Set & Day-Min & Day-Max & Night-Min & Night-Max \\
\hline Location & RN 1 & 69 & 74 & 70 & 74 \\
& RN 2 & 68 & 73 & 68 & 74 \\
\hline (RN - Registered Nurse) & & & &
\end{tabular}


baseline measurement. Seven weeks after the implementation of the intervention, the noise levels were between $49 \mathrm{dBA}$ (Night-Min in PR 2) and $81 \mathrm{dBA}$ (Day-Max for RN 1), and 15 weeks after the beginning of the intervention, levels were between 68 (Day-Min) and 74 dBA (Night-Max). The data for patient room 1, patient room 2, and nurse station in Table 3 are unavailable due to a technical issue. Overall, the noise $\left(\mathrm{L}_{\mathrm{Aeq}}\right)$ varied between $47 \mathrm{dBA}$ (Night-Min) and $81 \mathrm{dBA}$ (Day-Max). As expected, day shifts generally had higher noise levels than night shifts.

The nursing station showed noise levels in the range of $52 \mathrm{dBA}$ (Night-Min) to 59 dBA (Day-Max) for the baseline measurement, and between 52 dBA (Night-Min) and $58 \mathrm{dBA}$ (Day-Max) seven weeks after the implementation of the intervention. There is not much variation in the pre-and post-intervention values. There was a small room next to nursing station for the nurses to sit and relax. The noise levels at the nursing station might have been reduced because of the existence of that room.

\subsection{Patient Rooms}

Figures 1 and 2 reveal that the $\mathrm{L}_{\mathrm{Aeq}, 12 \mathrm{~h}}$ noise levels in patient rooms 1 and 2 varied approximately between $47 \mathrm{dBA}$ and $69 \mathrm{dBA}$, while $\mathrm{L}_{\mathrm{CPeak}}$ varied between $100 \mathrm{dBC}$ and $124 \mathrm{dBC}$. The octave band frequency analysis presented in Figure 3 for patient room 1 shows that pre- and post-intervention measurements are similar across frequencies from 31.5 to $4,000 \mathrm{~Hz}$, however, at higher frequencies of 8,000 and $16,000 \mathrm{~Hz}$, postintervention noise levels increased. Figure 4 shows the frequency analysis of the noise in patient room 2 .

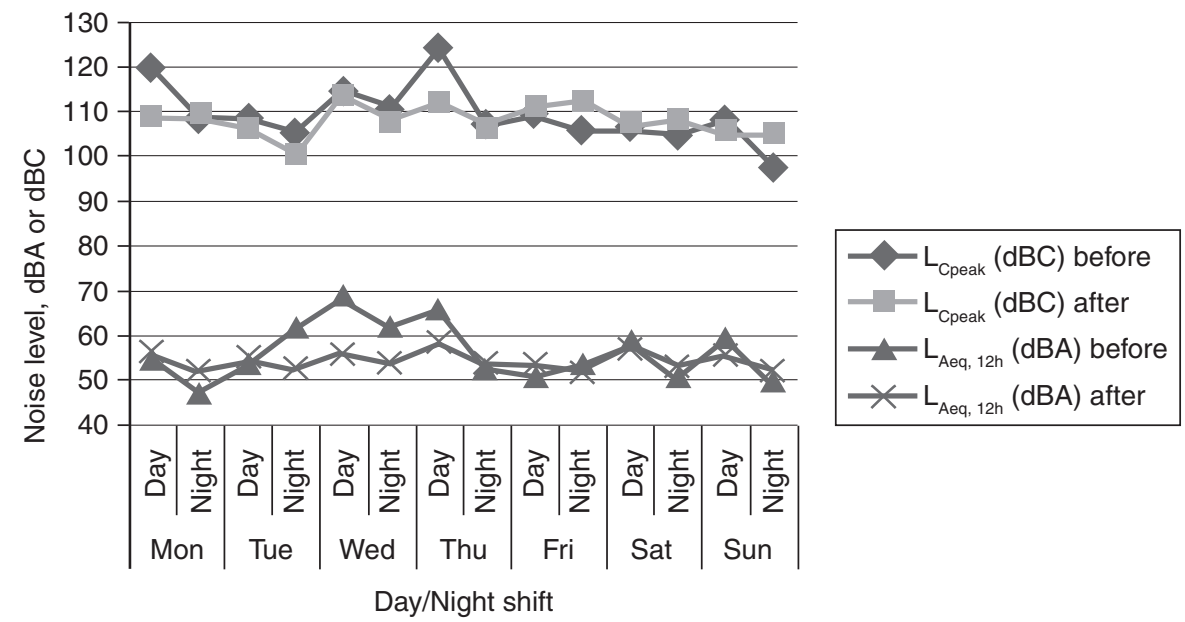

Figure 1. Variation of noise levels in patient room \# 1 before and after the 7-week intervention. 

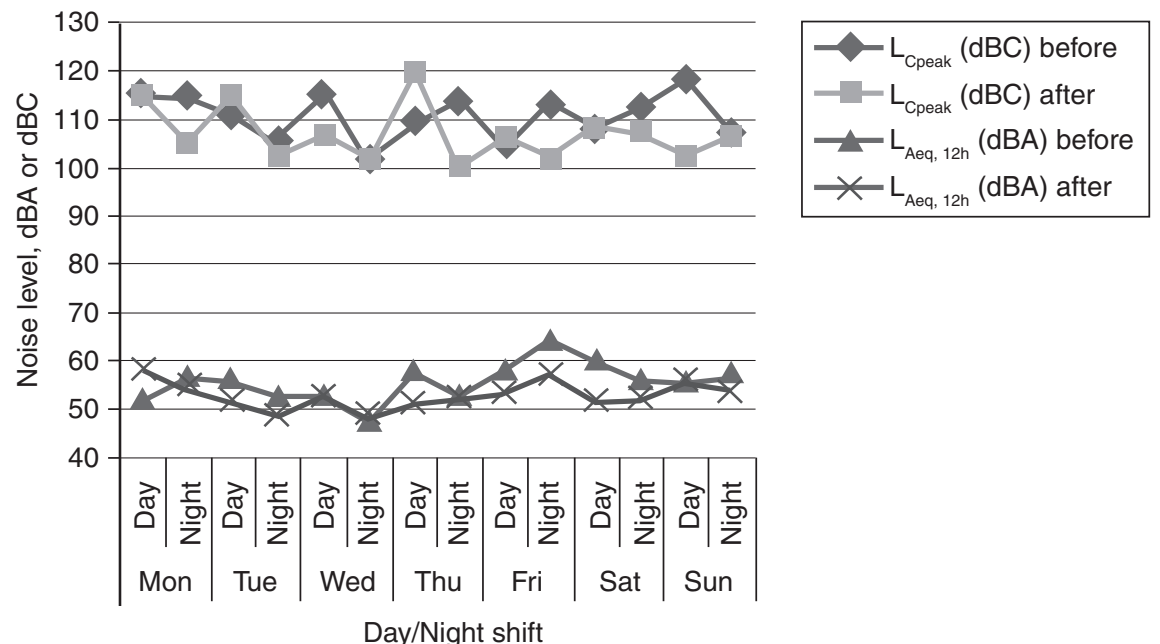

Figure 2. Variation of noise levels in patient room \# 2 before and after the 7-week intervention.

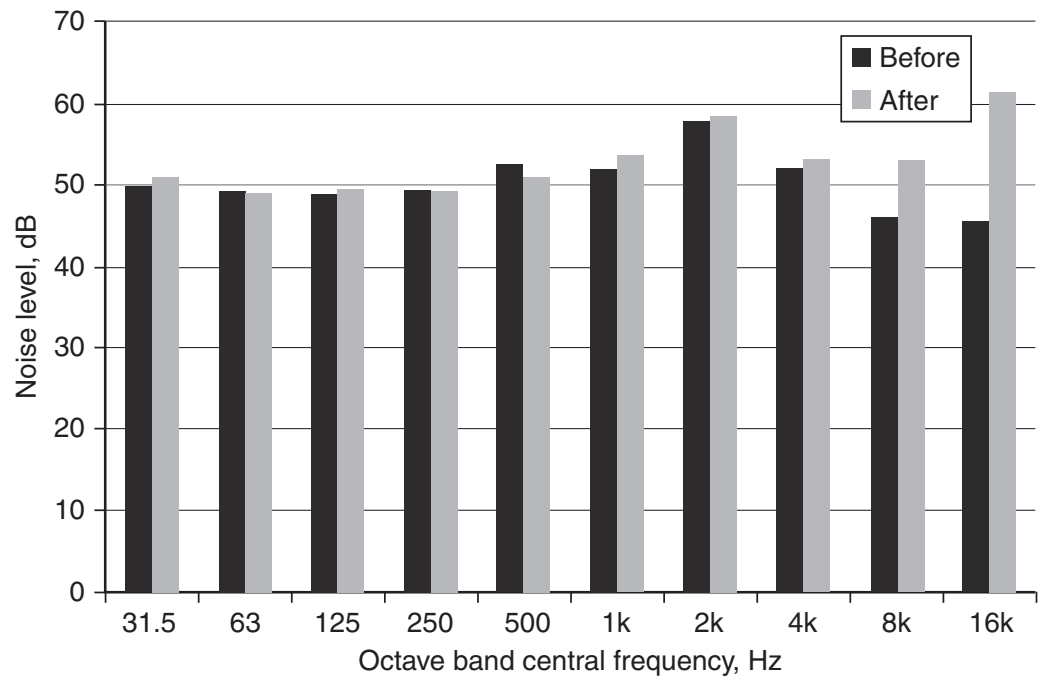

Figure 3. Octave band frequency analysis of the noise in patient room \# 1 over a week before and after the 7 -week intervention. Noise level data are unweighted, referenced to 20 micropascals. 


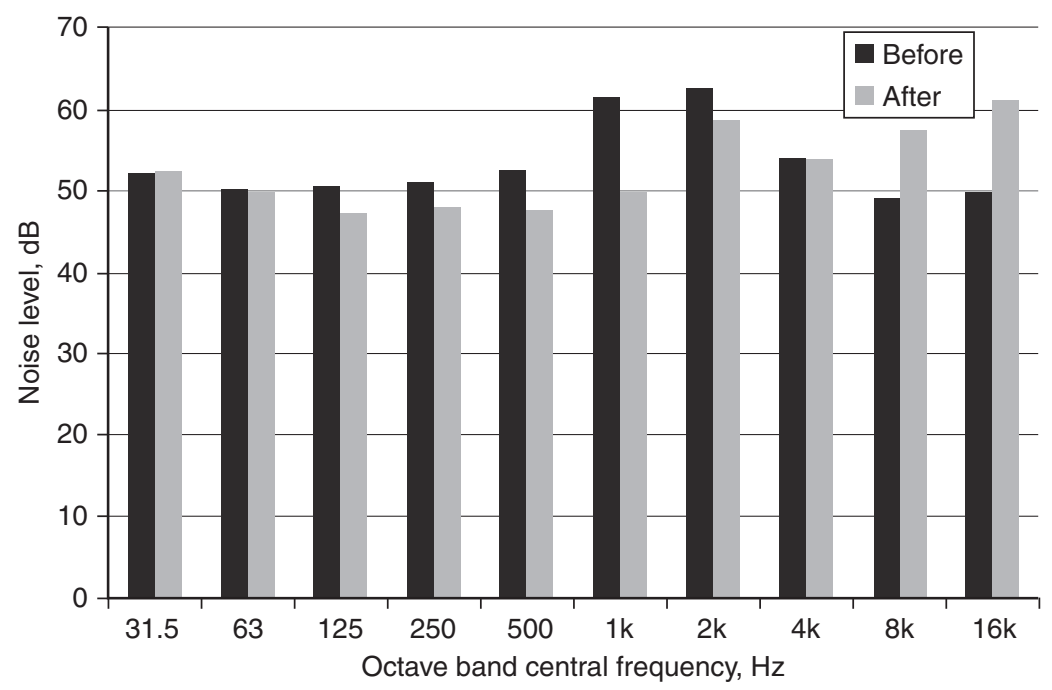

Figure 4. Octave band frequency analysis of the noise in patient room \# 2 over a week before and after the 7-week intervention. Noise level data are unweighted, referenced to 20 micropascals.
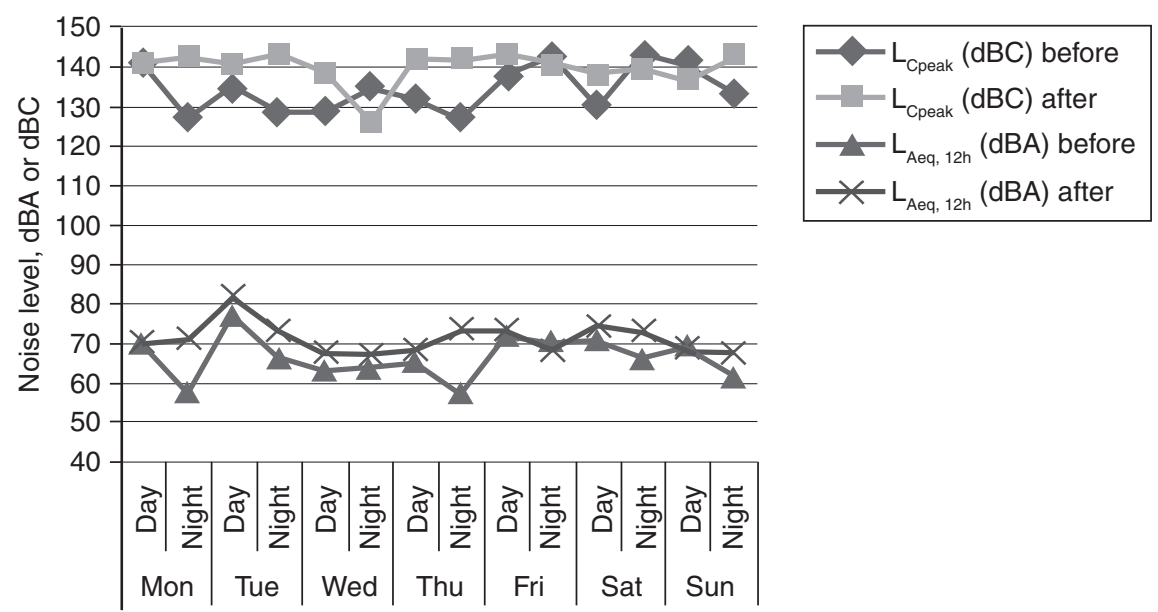

Day/Night shift

Figure 5. Noise experienced by RN 1 before and after 7-week intervention.

\subsection{Nursing Staff}

Figures 5 and 6 show that the nursing staff (RN 1 and RN 2) experienced $L_{\text {Aeq, 12h }}$ noise levels approximately between $58 \mathrm{dBA}$ and $81 \mathrm{dBA}$, and the maximum values of $\mathrm{L}_{\mathrm{CPeak}}$ varied between $115 \mathrm{dBC}$ and $146 \mathrm{dBC}$. (DoseBadge meters do not provide frequency analysis of these data.) 

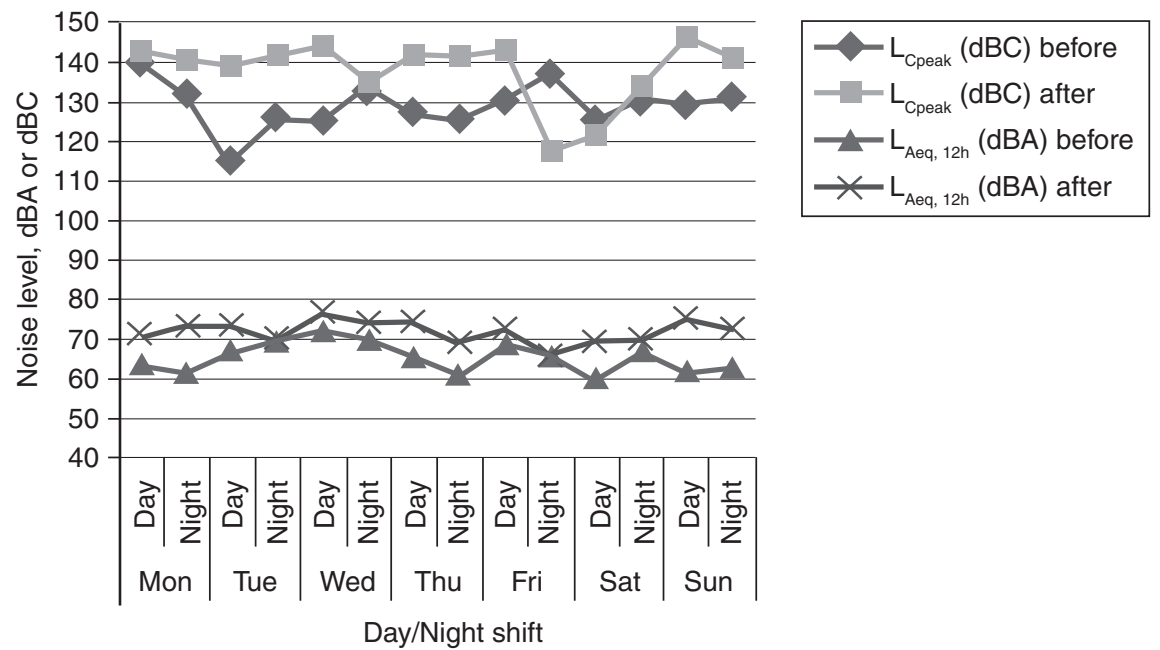

Figure 6. Noise experienced by RN 2 before and after the 7-week intervention.
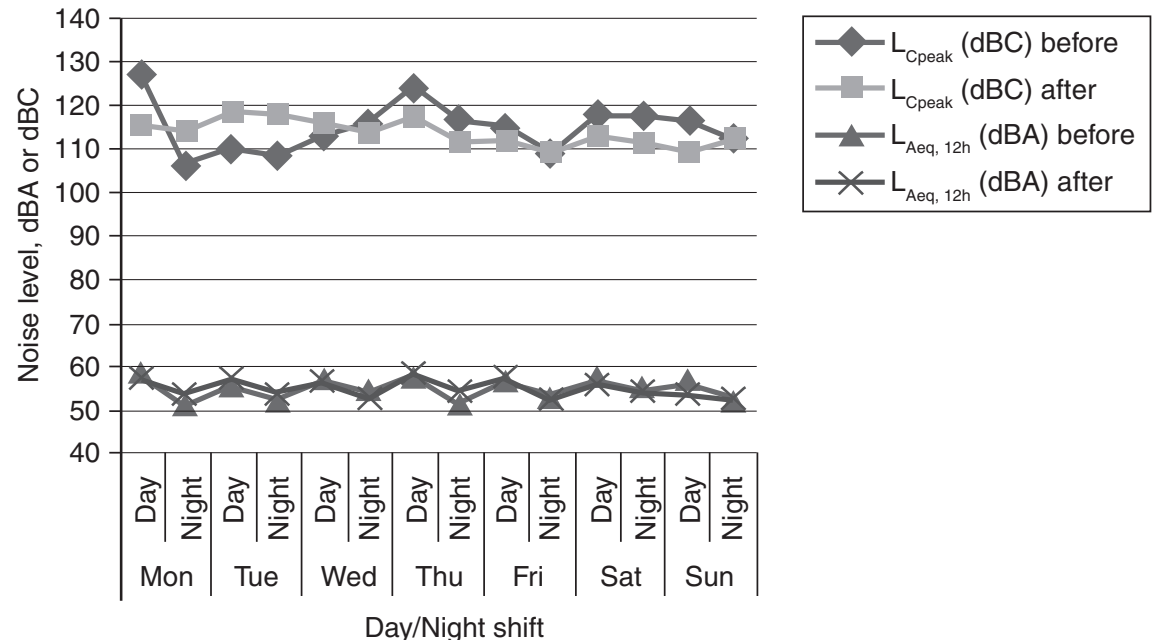

Figure 7. Noise levels at the nursing station before and after the 7-week intervention.

\subsection{Nursing Station}

The nursing station recorded $\mathrm{L}_{\mathrm{Aeq}, 12 \mathrm{~h}}$ noise levels between $50 \mathrm{dBA}$ and $60 \mathrm{dBA}$, as indicated in the Figure 7, whereas the peaks $\mathrm{L}_{\mathrm{CPeak}}$ varied between $108 \mathrm{dBC}$ and 128 $\mathrm{dBC}$. The frequency analysis (Figure 8) reveals no significant variation between low and high frequencies.

We carried out an octave band frequency analysis of the noise from the patient rooms and the nursing station. The frequency spectrum of two patient rooms 


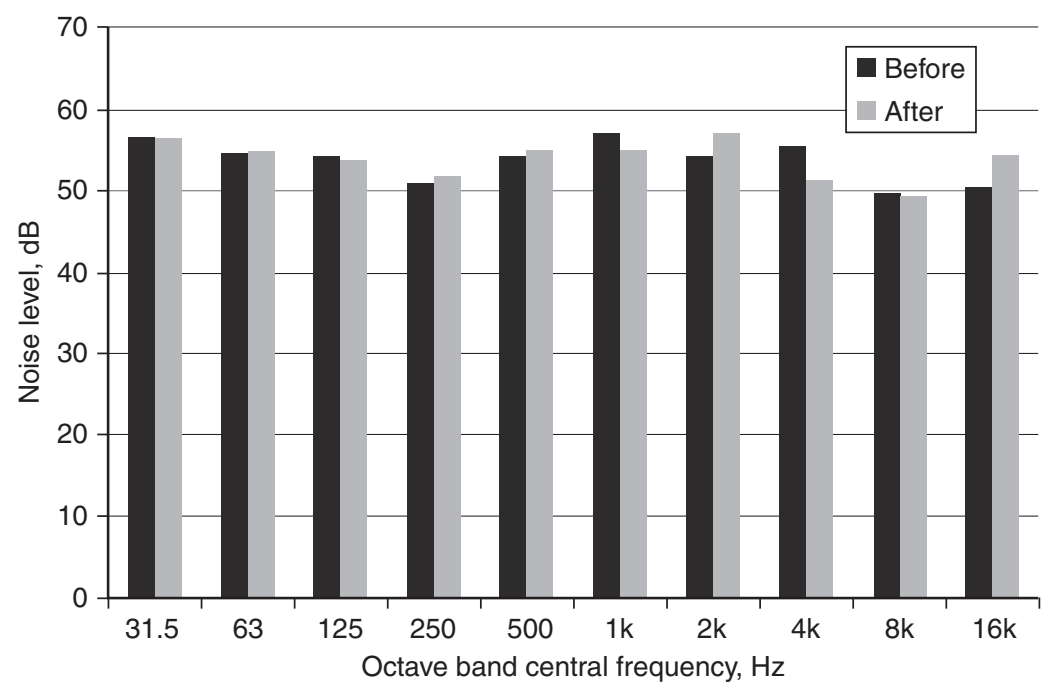

Figure 8. Octave band frequency analysis of the noise at nursing station over a week before and after the 7-week intervention. Noise level data are unweighted, referenced to 20 micropascals.

(Figures 3 and 4) reveals that the noise levels between $31.5-125 \mathrm{~Hz}$ were between 48 and $52 \mathrm{~dB}$, and were almost constant. The octave bands of 500 to $8,000 \mathrm{~Hz}$ were above $45 \mathrm{~dB}$ and noise levels in the frequency range $1,000 \mathrm{~Hz}$ and 2,000 $\mathrm{Hz}$ were between 50 and $60 \mathrm{~dB}$. For the nursing station, as indicated in Figure 8, noise levels were between 50 and $57 \mathrm{~dB}$ in the frequency range of $31.5-16,000 \mathrm{~Hz}$.

\section{DISCUSSION}

The noise amplitude and frequency analysis of the PICU environment supported previous findings that hospital nursing staff and patients generally experience excessive noise $\left(\mathrm{L}_{\mathrm{Aeq}}>50 \mathrm{dBA}\right)$. The frequency analysis quantitatively supported previous assertions that the sources of ICU noise most prominently include false medical device alarms, noise generated by conversation of the staff and visitors, and the low frequency noise generated by ventilation system.

Most published studies involving the measurement of acoustical levels in hospital ICUs measured noise levels from stationary sound level meters; they also measured the noise levels for much shorter periods of time than our study (for example, the measurements were for a few hours to a day or, at most, two to three days). Only a few studies have measured the noise experienced by nursing staff wearing noise dosimeters. Among the other unique aspects of our study is that it was conducted in a private room style ICU, which provides better noise control as compared to multibed rooms (shared room) ICUs. Moreover, noise levels were measured from five locations/personnel (from patient's rooms; in the central nursing station; and finally, on the mobile nursing staff themselves, using doseBadge noise dosimeters) to 
understand the variation in the noise characteristics in PICU. Also unique in our study is that we measured the noise levels in three different phases over an extended period of time to evaluate the long term effectiveness of the intervention. In each phase, noise levels were recorded continuously for 7 days (24 hours $\times 7$ days) and the time sampling rate for each integrating sound level meter (ISLM) was set as one second. (The "time sampling rate" means that the noise was recorded as an integral over one second of time. In this sense, the ISLM is similar to the dosimeter-it determines equivalent sound levels over a measurement period by supplying a single reading of a given noise, even if the actual sound level of the noise changes continually.)

In patient rooms, the noise level varied between $47 \mathrm{dBA}$ (Night-Min) and $69 \mathrm{dBA}$ (Day-Max) during the baseline noise level recordings. Seven weeks after the beginning of intervention, the noise levels were in the range of $49 \mathrm{dBA}$ (Night-Min) to $58 \mathrm{dBA}$ (Day-Max). The maximum day time noise level decreased by $10 \mathrm{dBA}$ compared to baseline. The PICU has private rooms for each patient, which makes it less noisy than a shared-bed ICU[47]. Lawson and her colleagues state that the $\mathrm{L}_{\text {Aeq }}$ values were higher a patient room's door open as compared to closed [10]. Perhaps for this reason, the minimum noise levels in the patient rooms involved in our study were 47 to $48 \mathrm{dBA}$ very close to the EPA guideline of $45 \mathrm{dBA}$ for hospital environments. We have not taken any formal feedback, but virtually every nurse mentioned that the SoundEar was "always on." The above results support the fact that the noise levels were well above the recommended noise levels for hospital settings. Nursing staff are clearly experiencing excessive noise. Ryherd et al. measured noise levels using a dosimeter for 5 days and found that the nursing staff had experienced noise $\left(\mathrm{L}_{\mathrm{Aeq}}\right)$ in the range of 65 to $71 \mathrm{dBA}$, which accords with our observations. Our data also support their findings that the doseBadge dosimeters have measured higher $\mathrm{L}_{\text {Aeq }}$ and $\mathrm{L}_{\mathrm{CPeak}}$ noise levels than those made by the integrating sound level meters [50]. Padmakumar and his colleagues studied the noise levels in two ICUs of two large teaching hospitals in the UK. They found that noise level for one unit varied between 36.6 to $80 \mathrm{dBA}$ and for another unit, noise level varied between 40.6 and 86.2 dBA [4]. These results support our findings that ICUs are noisy and the noise levels are well above the recommended levels.

Unfortunately, behavioral modification only is effective if it is reinforced over a significant period of time and if those involved in the study believe it will work [51]. However, it is evident from our study that attempts at behavior modification alone do not appear to be effective in reducing noise levels. These observations are reinforced by those of critical care nurse Maurene Harvey, who noted in a recent editorial article: "In my 45-year career as a critical care nurse, ICU noise is one of the few things that, rather than improving, is getting worse" [51]. Harvey strongly supports "making sound reduction a high priority, starting a noise reduction process improvement team, and applying process improvement skills [to] create a quieter ICU environment" [51]. Moreover, a 2009 study [52], "Staff Solutions for Noise Reduction in the Workplace," found that "It is essential to involve committed, energized bedside staff if success is to be achieved" [52]. The positive involvement of patient's families and hospital administrators was shown to be critical in the reduction in noise levels. Our findings 
also supported previous results indicating that endorsement by supervisors is key as to whether an intervention is adopted by medical service workers [53].

In our study, noise levels may have increased in some instances because the number of patients in the unit increased after the intervention began as compared with baseline, implying more medical devices, more visitors, and more clinicians. Levels may have increased as well as a result of the Hawthorne effect; i.e., nurses were quieter during the initial assessment of noise because they knew we were monitoring the noise levels prior to giving information to them regarding how to reduce the levels.

\subsection{Frequency Analysis of the Noise}

The convention in the acoustical community is to report un-weighted $(\mathrm{dB})$ octave band sound levels in frequency analyses; therefore, the sound pressure levels discussed in this section are in $\mathrm{dB}$ referenced to 20 micropascals. Using an octave band filter for frequency analysis, we found that the PICU has noise in high audio frequencies. The frequency range of 31.5 to $16,000 \mathrm{~Hz}$ (octave bands) had sound pressure levels ranging from 50 to $60 \mathrm{~dB}$, with highest peaks (around $60 \mathrm{~dB}$ ) from 1000 to $4000 \mathrm{~Hz}$. The sources of the low frequency noise in the ICU settings are believed to be airborne, i.e., arising from the ventilation systems [54]. According to Berglund et al. [26], the low-frequency noise has two sources: natural or artificial. For example, air turbulence, wind and thunder are natural sources, whereas heating and air-conditioning systems, along with loudspeakers, are artificial sources. Thus, we conclude that the major sources of low frequency noise in the PICU are the ventilating systems and loudspeaker systems.

In an effort to characterize the sound spectrum of a Neurological ICU, Ryherd and colleagues [50] considered frequencies below $500 \mathrm{~Hz}$ as low frequencies; frequencies between $1000 \mathrm{~Hz}$ and $8000 \mathrm{~Hz}$ as high frequencies; and the frequency range of $125 \mathrm{~Hz}$ to $500 \mathrm{~Hz}$ as midfrequencies. They concluded that the Neurological ICU is dominated by high frequency noise [50]. In their study in a Neonatal ICU, Livera et al. also concluded that the Neonatal ICU was dominated by high frequency noise in the range from 1000 to $8000 \mathrm{~Hz}$ [55]. In our study, we found that patient rooms were dominated by high frequency components, whereas the central nursing station was dominated by mix of low and high frequency components. Research literature suggests that medical device alarms, mobile medical equipment and high velocity air flow in heating and cooling systems could be sources of high frequency noise [54]. Livera et al. carried out a frequency analysis of the noise generated by the medical equipment in a Neonatal Intensive Care Unit, and concluded that average noise levels between 1000 to $8000 \mathrm{~Hz}$ frequencies were around $69 \mathrm{~dB}$, and that the ventilators and incubators with alarms were the highest noise generators [55]. In a 2012 clinical review article by Ryherd et al., the researchers found that medical device alarms had a frequency range of 250 to $8000 \mathrm{~Hz}$, with sound pressure levels ranging from 54 to $84 \mathrm{dBA}$ [3]. Human speech energy is primarily concentrated in the 300 to $3000 \mathrm{~Hz}$ frequency range [30,56]. These findings support indications that the major sources of high frequency noise are medical devices alarms, ventilating systems and human speech. Because medical device alarms and 
natural conversations occur more frequently, they are considered to be the primary sources of noise.

Our findings are somewhat similar to the results of Busch-Vishniac et al.'s study [54], where the noise levels in the frequency range of $63-1000 \mathrm{~Hz}$ were found using an octave band filter to be between 50 to $60 \mathrm{~dB}$. Busch-Vishniac also noticed that the noise level was higher than $60 \mathrm{~dB}$ for frequencies of $63 \mathrm{~Hz}$ and lower. For frequencies between 1000 and $16000 \mathrm{~Hz}$, the noise levels decreased below $50 \mathrm{~dB}$ [54]. We see that noises in PICU appear to be predominantly composed of high frequency components. There is clearly a need to compare noise levels between different types of ICUs. Even more importantly, there is an urgent need for implementing effective strategies to reduce the noise (for example, reduction of number of false alarms).

\subsection{Limitations of the Study and Future Work}

This study has several important limitations. Patient rooms in which data were collected were not identical. Although the room layout was identical, the numbers and types of equipment varied from patient to patient. Patient census was higher during the follow-up phase of the study. More patients in the room would imply more unit activity and more noise. The study was not designed to capture exactly what generated noise or frequencies of particular noise 'generators'; therefore, we can only provide educated guesses on what is contributing the most noise and particular frequencies.

The study was designed to measure average noise levels over extended periods of time, not to measure the proportion of time decibel levels that were above a certain level. Carrying out analysis of such data may have been helpful in determining what was generating noise, and whether the 'topography' of the noise was characterized by very noisy versus very quiet times, or flatter, more constant noise levels.

In the course of implementing this study, we discovered the importance of minimizing the number of medical devices' false alarms. In our future work, we are planning to control the noise levels through a combined program of behavior modification coupled with medical device alarm management. It appears that customizing medical device alarms according to individual patient's condition may be a viable approach to reducing the number of false alarms. This suggests that future research should focus on development of smart alarms [57]. We would also like to develop a linear model for prediction of noise levels in an ICU, which could be useful in designing new ICUs.

\section{CONCLUSIONS}

We conclude that behavior modification programs are not effective in reducing noise levels. To efficiently reduce the noise levels, it is likely that a combined effective program to control the noise from the major sources, humans and machines, along with a continuous process improvement plan to reduce the noise, is required. We suggest that future new ICU designs should include considerations regarding engineering noise control and architectural design strategies to mitigate excessive noise levels. 


\section{ACKNOWLEDGEMENT}

This study is a part of the doctoral research work of the first author. We appreciate the patience and cooperation of all the nursing and administrative staff and the families of the patients of the PICU of the hospital. Without their constant support, this study could not have been possible.

\section{CONFLICT OF INTEREST}

The authors indicated no potential conflicts of interest.

\section{REFERENCES}

[1] Gurses AP, Carayon P. Performance obstacles of intensive care nurses. Nursing research. 2007, 56(3): 185-94.

[2] Choiniere D. The effects of hospital noise. Nursing Administration Quarterly. 2010, 34(4): 327-33.

[3] Ryherd EE, Okcu S, Ackerman J, Zimring C, Persson K, Waye PD. Noise pollution in hospitals: impacts on staff. Journal of Clinical Outcomes Management. 2012, 19(11): 491-500.

[4] Padmakumar A, Bhasin V, Wenham T, Bodenham A. Evaluation of noise levels in intensive care units in two large teaching hospitals - a prospective observational study. Journal of the Intensive Care Society. 2013, 14(3): 205-10.

[5] MacKenzie D, Galbrun L. Noise levels and noise sources in acute care hospital wards. Building Services Engineering Research and Technology. 2007, 28(2): 117-31.

[6] Morrison WE, Haas EC, Shaffner DH, Garrett ES, Fackler JC. Noise, stress, and annoyance in a pediatric intensive care unit. Critical Care Medicine. 2003, 31(1): 113-19.

[7] Christensen M. Noise levels in a general intensive care unit: a descriptive study. Nursing in Critical Care. 2007, 12(4): 188-97.

[8] Kahn DM, Cook TE, Carlisle CC, Nelson DL, Kramer NR, Millman RP. Identification and modification of environmental noise in an ICU setting. Chest. 1998, 114(2): 535-40.

[9] Tsiou C, Eftymiatos D, Theodossopoulou E, Notis P, Kiriakou K. Noise sources and levels in the Evgenidion hospital intensive care unit. Intensive Care Medicine. 1998, 24(8): 845-47.

[10] Lawson N, Thompson K, Saunders G, Saiz J, Richardson J, Brown D, Ince N, Caldwell M, Pope D. Sound intensity and noise evaluation in a critical care unit. American Journal of Critical Care. 2010, 19(6): E88-E99.

[11] Redding JS, Hargest TS, Minsky SH. How noisy is intensive care? Critical Care Medicine. 1977, 5(6): $275-76$

[12] Pugh RJ, Jones C, Griffiths RD. The impact of noise in the intensive care unit. In: Vincent JL, editor. Intensive Care Medicine: Springer New York; 2007. p. 942-49.

[13] Johansson L, Bergbom I, Waye KP, Ryherd E, Lindahl B. The sound environment in an ICU patient room-A content analysis of sound levels and patient experiences. Intensive and Critical Care Nursing. 2012, 28(5): 269-79.

[14] Buxton O, Ellenbogen J, Wang W, Carballeira A, O’Connor S, Cooper D, Gordhandas A, McKinney S, Solet J. Sleep disruption due to hospital noises A prospective evaluation. Annals of internal medicine. 2012, 157(3): 170-79.

[15] Meltzer LJ, Davis KF, Mindell JA. Patient and parent sleep in a children's hospital. Pediatric Nursing. 2012, 38(2): 64-71.

[16] Morton JA. Notes on noise. Nursing2013. 2013, 43(5): 37-40.

[17] Solet JM, Barach PR. Managing alarm fatigue in cardiac care. Progress in Pediatric Cardiology. 2012, 33(1): 85-90. 
[18] Ortiga J, Kanapathipillai S, Daly B, Hilbers J, Varndell W, Short A. The sound of urgency understanding noise in the emergency department. Music and Medicine. 2013, 5(1): 44-51.

[19] Johnson AN. Adapting the neonatal intensive care environment to decrease noise. Perinatal and Neonatal Nursing. 2003, 17(4): 280-88.

[20] Dennis CM, Lee R, Woodard EK, Szalaj JJ, Walker CA. Benefits of quiet time for neuro-intensive care patients. Journal of Neuroscience Nursing. 2010, 42(4): 217-24.

[21] Taylor-Ford R, Catlin A, LaPlante M, Weinke C. Effect of a noise reduction program on a medicalsurgical unit. Clinical Nursing Research. 2008, 17(2): 74-88.

[22] Allaouchiche B, Duflo F, Debon R, Bergeret A, Chassard D. Noise in the postanaesthesia care unit. British Journal of Anaesthesia. 2002, 88(3): 369-73.

[23] Macedo ISC, Mateus DC, Costa EDMGC, Asprino ACL, Lourenco EA. Noise assessment in intensive care units. Brazilian Journal Of Otorhinolaryngology. 2009, 75(6): 844-46.

[24] Matook SA, Sullivan MC, Salisbury A, Miller RJ, Lester BM. Variations of NICU sound by location and time of day. Neonatal Network. 2010, 29(2): 87-95.

[25] OSHA Appendix I: A Physics of Sound. Available: http://www.osha.gov/dts/sosta/otm/noise/healtheffects/physics.html Accessed Aug 08, 2013.

[26] Berglund B, Hassmen P, Job RFS. Sources and effects of low-frequency noise. Journal of the Acoustical Society of America. 1996, 99(5): 2985-3002.

[27] Smith SW. Audio processing. 1997. Available from: http://www.dspguide.com/ch22/1.htm. Accessed Aug 08, 2013.

[28] Pope DS, Gallun FJ, Kampel S. Effect of hospital noise on patients' ability to hear, understand, and recall speech. Research in Nursing \& Health. 2013, 36(3): 228-41.

[29] Ryherd EE, Moeller Jr M, Hsu T. Speech intelligibility in hospitals. Journal of the Acoustical Society of America. 2013, 134(1): 586-95.

[30] Berglund B, Lindvall T, Schwela D. Guidelines for community noise. World Health Organization. 1999. Available from: http://www.who.int/docstore/peh/noise/guidelines2.html. Accessed Aug 08, 2013.

[31] Cvach M. Monitor alarm fatigue: an integrative review. Biomedical Instrumentation \& Technology. 2012, 46(4): 268-77.

[32] Hsu T, Ryherd E, Persson W, Ackerman J. Noise pollution in hospitals: impact on patients. Journal of Clinical Outcomes Management. 2012, 19(7): 301-09.

[33] Sundstrom E, Town JP, Rice RW, Osborn DP, Brill M. Office noise, satisfaction, and performance. Environment and Behavior. 1994, 26(2): 195-222.

[34] Konkani A, Oakley B. Noise in hospital intensive care units: A critical review of a critical topic. Journal of Critical Care. 2012, 27 (5): 522.e1-22.e9.

[35] Landro L. Hospitals work on patients' most-frequent complaint: Noise. The Wall Street Journal 2013. Available from: http://online.wsj.com/article/B10001424127887324634304578537350035525538.html. Accessed Aug 11, 2013.

[36] Sun L H. Too much noise from hospital alarms poses risk for patients. The Washington Post. 2013. Available from: http://www.washingtonpost.com/sf/feature/wp/2013/07/07/too-much-noise-fromhospital-alarms-poses-risk-for-patients/. Accessed Aug 11, 2013.

[37] Fox News. Typical hospital noises may disrupt sleep. Fox News. 2012. Available from: http://www.foxnews.com/health/2012/06/12/typical-hospital-noises-may-disrupt-sleep/. Accessed Aug 11, 2013.

[38] Reddy S. How hospital noise harms health. ABC News. 2012. Available from: http://abcnews.go.com/Health/hospital-noise-harms-health/story?id=16543497. Accessed Aug 11, 2013. 
[39] Neergaard L. Hospital sounds disturb patients' sleep, study shows. 2012. Available from: http://www.huffingtonpost.com/2012/06/12/hospital-sounds-sleep-patients-disturb_n_1589834.html. Accessed Aug 11, 2013.

[40] Kowalczyk L. Noisy treatment in hospitals: Loud patient rooms and floors can hinder restful recuperations. The Boston Globe.2011. Available from:

http://www.boston.com/lifestyle/health/articles/2011/10/3/noisy_treatment_in_hospitals/. Accessed Oct 2, 2013

[41] Sanders MS, McCormick EJ. Chapter 18 : Noise. Human factors in engineering and design. 7th ed: Mcgraw-Hill Book Company; 1993. p. 589-621.

[42] Philbin M. Planning the acoustic environment of a neonatal intensive care unit. Clinics in Perinatology. 2004, 31(2): 331.

[43] Zahr LK, de Traversay J. Premature infant responses to noise reduction by earmuffs: effects on behavioral and physiologic measures. Journal of Perinatology. 1995, 15(6): 448-55.

[44] Wallace CJ, Robins J, RPSGT B, Alvord LS, Walker JM. The effect of earplugs on sleep measures during exposure to simulated intensive care unit noise. American Journal of Critical Care. 1999, 8(4): $210-19$.

[45] Thompson DR, Hamilton DK, Cadenhead CD, Swoboda SM, Schwindel SM, Anderson DC, Schmitz EV, St Andre AC, Axon DC, Harrell JW. Guidelines for intensive care unit design. Critical Care Medicine. 2012, 40(5): 1586-600.

[46] Herman Miller. Inc. Sound practices: noise control in the healthcare environment-research summary. Herman Miller, Inc., Zeeland, Michigan. 2006. Available from: http://www.hermanmiller.com/ MarketFacingTech/hmc/research_summaries/pdfs/wp_Sound_Practices.pdf. Accessed Aug 8, 2013.

[47] Joseph A, Ulrich R. Sound control for improved outcomes in healthcare settings. The center for Health Design,Concord, $\backslash$ CA.2007. Available from:

http://www.healthdesign.org/sites/default/files/Sound\%20Control.pdf. Accessed Aug 8, 2013.

[48] U.S.Environmental Protection Agency (EPA).EPA Identifies Noise Levels Affecting Health and Welfare. 1974. Avilable from: http://www2.epa.gov/cache/normal/www2.epa.gov/aboutepa/epaidentifies-noise-levels-affecting-health-and-welfare html.Accessed Aug 8, 2013.

[49] U.S. Environmental Protection Agency. (The Noise Pollution Clearing House (NPC) Online Library). Condensed version of EPA Levels document. Washington, D.C. 20460.1974. Available from: http://www.nonoise.org/library/levels/levels.htm. Accessed Aug 8, 2013.

[50] Ryherd EE, Waye KP, Ljungkvist L. Characterizing noise and perceived work environment in a neurological intensive care unit. Journal of the Acoustical Society of America. 2008, 123(2): 747-56.

[51] Harvey.M.A. Quieter units—an achievable goal. Journal of Critical Care. 2012, 27(5): 516-17.

[52] Connor A, Ortiz E. Staff solutions for noise reduction in the workplace. Permanente Journal. 2009, 13(4): 23-27.

[53] Weiler MR, Lavender SA, Mac Crawford J, Reichelt PA, Conrad KM, Browne MW. Identification of factors that affect the adoption of an ergonomic intervention among Emergency Medical Service workers. Ergonomics. 2012, 55(11): 1362-72.

[54] Busch-Vishniac IJ, West JE, Barnhill C, Hunter T, Orellana D, Chivukula R. Noise levels in Johns Hopkins Hospital. Journal of the Acoustical Society of America. 2005, 118(6): 3629-45.

[55] Livera M, Priya B, Ramesh A, Suman Rao P, Srilakshmi V, Nagapoornima M, Ramakrishnan A, Dominic M. Spectral analysis of noise in the neonatal intensive care unit. Indian Journal of Pediatrics. 2008, 75(3): 217-22.

[56] Lamancusa JS. Noise control - human response to sound. 2000. Available from: http:// www.me.psu.edu/lamancusa/me458/3_human.pdf. Accessed Aug 8, 2013.

[57] Konkani A, Oakley B, Bauld TJ. Reducing hospital noise: A review of medical device alarm management. Biomedical Instrumentation \& Technology. 2012, 46(6): 478-87. 


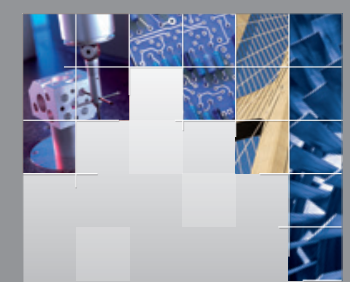

\section{Enfincering}
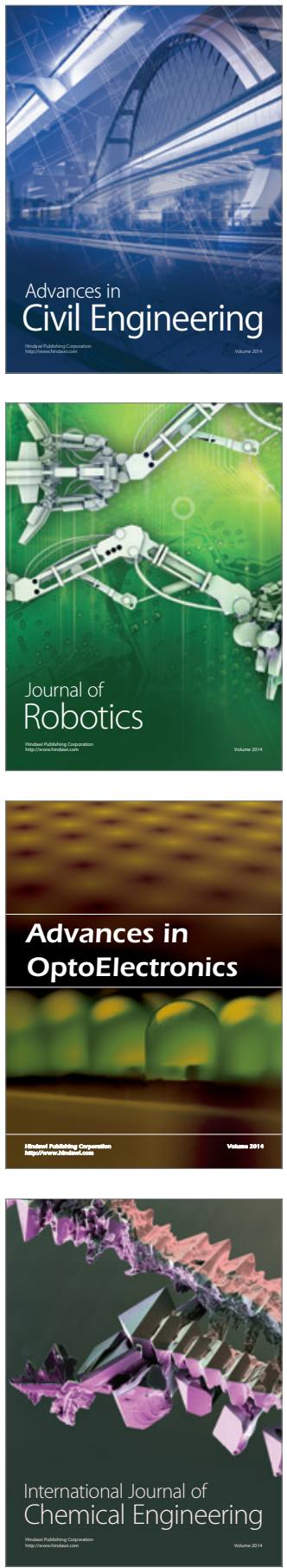

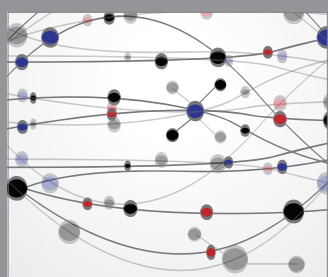

The Scientific World Journal

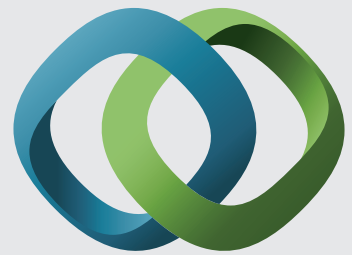

\section{Hindawi}

Submit your manuscripts at

http://www.hindawi.com
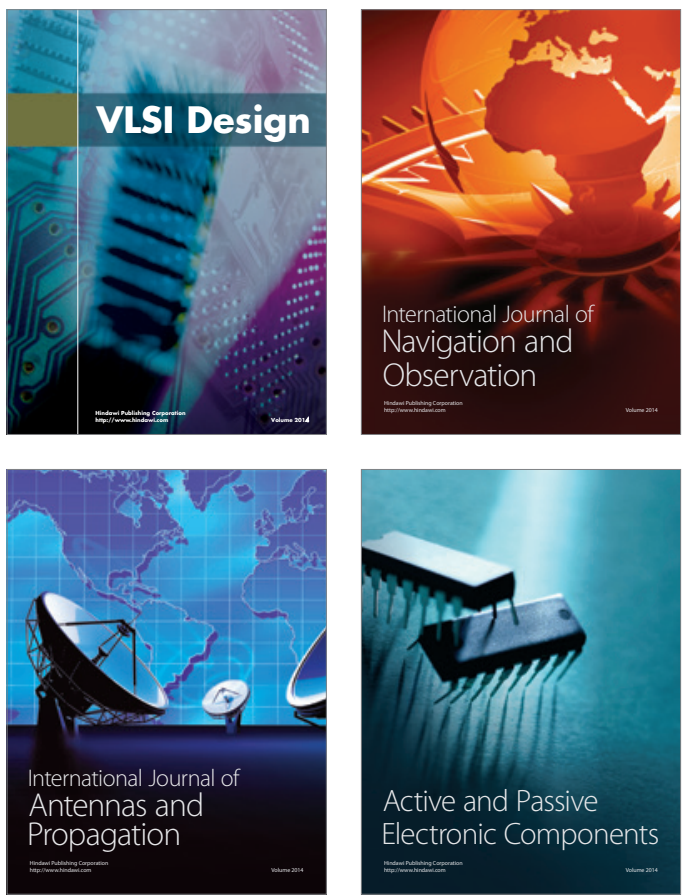
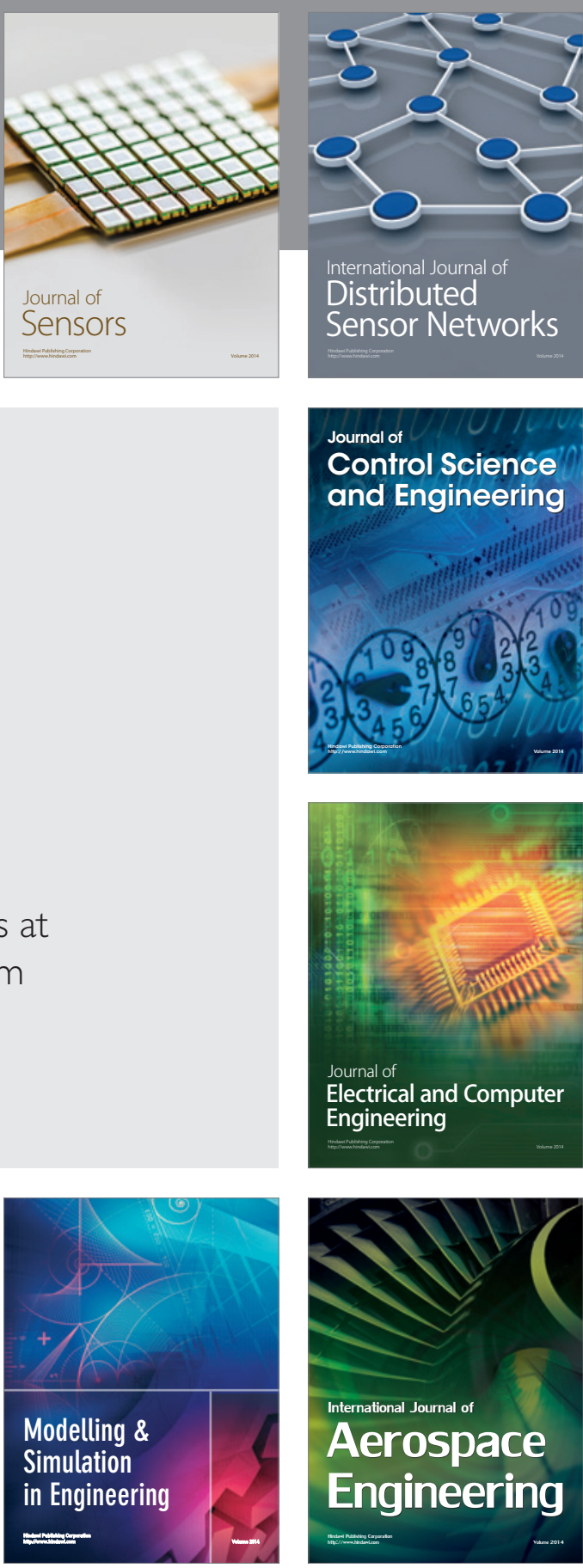

International Journal of

Distributed

Sensor Networks

Journal of

Control Science

and Engineering
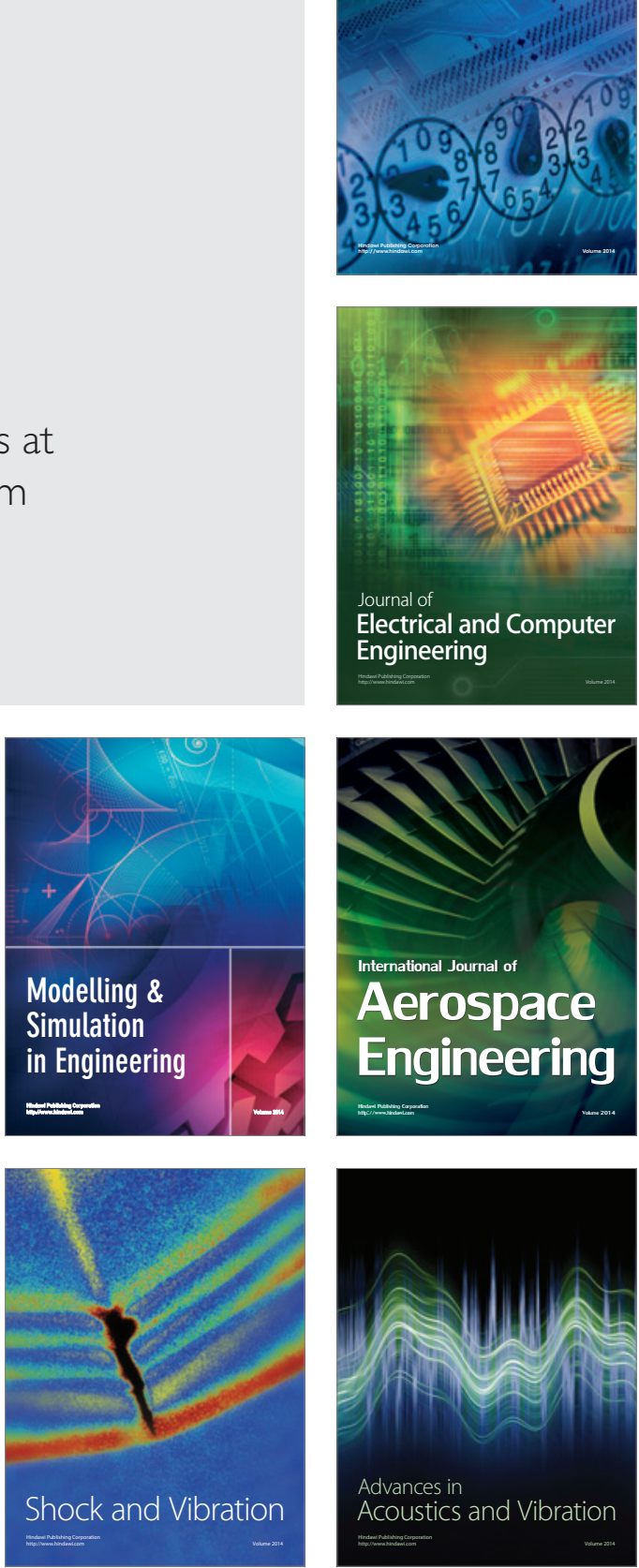